\title{
ENGLISH FOR PHARMACY: AN ESP COURSE IN A CLIL CONTEXT
}

Monika Woźniak, Desirée Acebes de la Arada

Universidad San Jorge, Spain

Phone: +34976060 100, E-Mail: mwozniak@usj.es, dacebes@usj.es

\begin{abstract}
This article deals with an ESP course taught as an obligatory subject in a pharmacy undergraduate degree programme in Spain. The language course is only one of the contexts involving disciplinary English as the degree programme integrates English in several content subjects. The ESP course is an attempt to find the right balance between students' language needs, pharmacy-specific language skills, and the language-related demands of pharmacy content subjects which integrate English. The co-existence of ESP and CLIL teaching is seen as an opportunity for a closer cooperation and coordination with disciplinary experts to make connections between disciplines and activities towards better learning outcomes. We propose a course aimed at raising students' language awareness through focused tasks which will cater to student's communicative needs related to the two main themes of the course: chemistry and pharmaceutical care.
\end{abstract}

Key words: course design, university teaching, pharmacy, teacher collaboration, ESP, $E M I / C L I L$

\section{INTRODUCTION}

ESP (English for Specific Purposes) language courses aim to address students' specialised needs and expectations relevant for their respective academic disciplines and professional domains (Hutchinson \& Waters, 1987). ESP courses, rather than general English courses, are then a good occasion to introduce university level students to disciplinary language and communication in their respective areas. Nonetheless, today disciplinary language is more and more present beyond language-centred courses in university settings around the world. The implementation of English through approaches like EMI (English-medium instruction) or CLIL (Content and Language Integrated Learning), or other local varieties based on them, changes the situation of ESP teaching. Whereas EMI refers mainly to the use of English as a medium of instruction with the focus placed on content learning outcomes and no explicit attention to language learning issues (Airey, 2016), CLIL is a dual-focused educational approach which aims to accommodate the learning of content and language, albeit the two elements do not have to be pursued always to the same extent (Coyle, Hood \& Marsh, 2010). On the languagecontent continuum, Airey (2016: 73) places CLIL in the middle between EAP (English for Academic Purposes) and English-medium instruction, though underlines the artificial nature of such a division due to the close and inseparable link between language and content. However, as regards teaching at university level, it is usually EMI rather than

Submitted April 30 $30^{\text {th }}, 2018$, accepted for publication October $3^{\text {rd }}, 2018$ 
CLIL that is in reality implemented since lecturers tend to concentrate on content learning outcomes and view content teaching as their main responsibility (Airey, 2017: 74). On the other hand, ESP lecturers are more open to the integration of content learning in their courses and ESP courses are still the main settings in which disciplinary language learning is properly assessed (Yang, 2016).

Despite this growing amount of disciplinary English across the subjects, students' language learning outside language courses is often only incidental, so ESP and EMI/CLIL teaching can still co-exist and complement each other, especially in nonEnglish speaking countries. Next to new challenges, the two approaches within the same institution can trigger changes and innovations in traditional ESP courses to better adapt them to students' communicative needs as well as generate enriching opportunities for interdisciplinary collaborative initiatives (Arnó-Macià \& Mancho-Barés, 2015; González Ardeo, 2013; Woźniak, 2017). Leonardi (2015) shows that ESP and CLIL at university level overlap in their focus on communicative, task-based activities or authentic tailored materials adapted to the needs of students who lack content knowledge and acquire it at the same time as English. These convergence points, coupled with the growing amount of English used in content subjects, may call for more integrated approaches to ESP teaching in search of more active and meaningful learning. Nonetheless, Tarnopolsky (2013) defends traditional language-focused ESP courses at the beginning of university studies to raise student' awareness of the peculiarities of disciplinary language and communication and help to catch up on English language deficiencies which may still exist. More integrated approaches can be more appropriate for the following years of studies when students have acquired more knowledge about their area of study and future profession. Such a progression towards more integrated approaches seems justifiable if we consider that ESP course in the initial years of university will not be able to reflect and replicate the complexities of professional communication as students do not know in what situations they are likely to use English.

After this brief outline of the current situation of ESP and the increasingly blurred dividing line between content and language teaching and learning at university level, in what follows we report on the practical realisation of a pharmacy ESP course taught in a CLIL degree programme in Spain. More specifically, we delve into its content, vocabulary exercises and assessment tasks developed for the course.

\section{ENGLISH FOR PHARMACY: CONTEXT AND NEEDS ANALYSIS}

The institution described in this article approaches English in its undergraduate degree programmes in two ways. English is taught in ESP-based courses specifically designed for each degree programme and is also integrated in selected content subjects through a university-wide CLIL programme. Many ESP lecturers are actively involved in the implementation of CLIL in assigned degree programmes by providing support, guidance and supervision to teachers who undertake CLIL teaching (see Woźniak, 2017). In the Pharmacy degree, the ESP subject is a six-credit course (150 hours divided into in-class and autonomous work) taught in the second semester of the first year. The classes are taught twice a week to groups of approximately 20 Spanish students. Although there is no official English language level prerequisite to enrol on the course, B1 is considered the minimum level to pursue the subject successfully. The course was incorporated into the 
official curriculum of the degree programme after the implementation of CLIL, so its design had to consider all the English language already integrated in content subjects. As a result, the course was designed to serve the needs of the students who encounter the challenge of studying some parts of academic content knowledge through English and lecturers who teach their non-linguistic academic contents through English. To gain insights into the overall presence of English across the subjects and identify the needs which CLIL activities do not fulfil, we conducted interviews with content lecturers as subject area experts in search of connections between content and language subjects and using a pharmaceutical metaphor - find the optimal dosage of English across the subjects (see García et al., 2018; Woźniak et al., 2016).

The ESP language course was expected to complement the disciplinary language learning needs and assist the activities students will complete in English in content subjects, but simultaneously still maintain the position of an independent subject, with its own objectives, planning and decisions. Considering the expectations and needs identified, one of the first tasks was to understand the tasks pharmacists are required to perform in English and decide on relevant thematic areas to be incorporated in the course. First-year students' knowledge about the subject matter is still very limited and they do not know a real context for the vocabulary and structures they will study, so our activities cannot closely resemble future professional tasks. As far as language learning is concerned, focused tasks are designed to prompt learners to use specific linguistic features, whereas unfocused tasks are designed to encourage communication in general (Ellis, 2009). The overview of activities conducted in English across the subjects allowed us to decide which meaning-focused tasks can prove more effective with content lecturers and are thus more suitable for CLIL activities in content subjects. As disciplinary insiders, content lecturers can better address students' content-related queries, for example, when writing a research article or a laboratory report. However, often unaware of language considerations and feeling responsible for content learning outcomes, content specialists primarily use English as a means for content learning and only to a limited extent as an aim in itself. Our main aim was to incorporate activities and tasks which would interrelate with other academic activities performed in English and would help students complete their tasks in English and thus prepare them for professional activities in the future.

Having the overall analysis of the needs in the light of CLIL activities conducted in English, we opted for an eclectic, mainly exercise-based approach that would integrate different language skills and satisfy students' language needs concerning specialist vocabulary and structures used in disciplinary communication. Our course is based on focused production tasks in which students will attend to form while engaged in language use for pharmacy-related communication. Despite the focus on language skills, some parts were still identified as requiring support from a subject specialist as disciplinary insider. At the beginning of each course, we ask students to complete an open-question questionnaire to know more about their previous learning experience and expectations regarding this ESP course as well as to uncover their first impressions of CLIL activities in content subjects in the first semester. At this stage, students generally appreciate the presence of the English language in content subject and their main expectations regarding the ESP subject are related to technical vocabulary and terminology. 


\section{EXPECTED LEARNING OUTCOMES AND COURSE CONTENT}

Students' workload, learning outcomes and evaluation categories for this course are established from the top down by the degree programme and are officially accredited by the national agency for evaluation and accreditation. As a result, the course needs to be created with these criteria in mind, but they still give us enough freedom to design it in a way which will best fit our students' and content lecturers' needs. In general terms, the expected learning outcomes can be summarised as the four practical language skills (reading, writing, listening and speaking) within the domain of pharmacy and healthcare. Given the distribution of CLIL activities in content subjects, we decided to divide the course into two parts which would parallel content learning through English outside the language class. The first part focuses on chemistry and coincides with practical classes in the laboratory. The second part of the course is dedicated to pharmaceutical care adapted to the limited content knowledge of first-year students. In this way, the ESP course is composed of eight short blocks covering the two main areas of chemistry and pharmaceutical care: Introduction to Pharmacy, Lab Safety, Chemistry, Experiments, Herbal Medicine, Drugs and Medicines, Illness and Disease, and Pharmaceutical Care. Given such a tailored nature of the course, commercial teaching materials are barely suitable, though not dismissed. As a matter of fact, the materials used in the course comprise a combination of original materials based on authentic texts which are specifically designed for the target group, along with a selection, often adapted, of published commercial materials from a range of books available on the market.

The evaluation criteria of the course include individual and group work, apart from progress tests and final exam. There are three individual assignments, one of which is done in class in writing. In order to maximize speaking time and evaluate pronunciation, the other two individual evaluated tasks are done outside of the class and consist in submitting audio recordings. At the end of each of the two main parts of the course students complete a pair or group assignment (see sections 3.2 and 3.3 for details). Students' work is evaluated with specially designed rubrics which help the teachers involved to use the same evaluation criteria and minimize subjectivity and differences between groups. More importantly perhaps, the rubrics also serve as learning organizers and can help the students to better understand the expectations and complete their work accordingly (Wolf \& Stevens, 2007). Although the subject focuses on language and communication, the division between evaluating content or language is not easy to delimit due to an inevitable overlap between content and language learning, hence the evaluation of some parts by a subject specialist. The following subsections give more details on the exercises and tasks performed throughout the course.

\subsection{Vocabulary learning for Pharmacy degree}

Vocabulary learning is an essential part of any language learning process, so the knowledge and use of technical specialized vocabulary is also one of the key concerns of ESP. Learners are expected to use specialized lexicon for effective communication with people inside a given area of study or professional activity. Not surprisingly, our students indicated specialized vocabulary within the area of pharmacy as their main expectation regarding this ESP course. Vocabulary exercises weave around the different activities throughout the course to build students' receptive and productive vocabulary, that is words that learners recognize and understand when they encounter them in reading or listening versus those they can produce in speaking and writing. The size of receptive 
vocabulary is normally larger than the productive one, whereas the sizes of the two types of lexicon are likely to correlate (Webb, 2008). A great part of technical vocabulary in English encompasses terms of Graeco-Latin origin which for native speakers of Spanish are easily recognizable in written texts, and thus make their receptive purposes in scientific English relatively easier. On the other hand, however, specialized vocabulary also encompasses apparently ordinary vocabulary used in everyday language and which takes on specific meanings when used in a particular academic or professional context, for example the verb dissolve (Coxhead, 2013: 116, 127). Warburton (2015: 362) notes, however, that "one cannot easily distinguish between general language (LGP) and special language (LSP)", which is particularly relevant for undergraduates in their initial year of the degree programme, as in our case. The use of English across the subjects may also result in using different terms by different lecturers, which may lead to misconceptions and confusion. For this reason, our consultations with content lecturers also serve to harmonise the terminology used and plan how to address the variations accordingly.

Although our students will use technical English to acquire specialised knowledge, read or write specialised texts and communicate in academic and professional situations, we must remember that they are still learners of English. In order to maximise the effects of this ESP course, our objective is to equip students with strategies for learning vocabulary as an active learning process that will improve their productive skills and foster their autonomy in building their vocabulary knowledge during and beyond the language course. With this aim in mind, the course also encompasses dictionary literacy viewed as a vocabulary learning strategy. The internet makes it easy to access scientific English and consult multiple dictionary resources and tools, though also generates new problems that deserve consideration. Given the growing number of non-native speakers who use English in academic and professional environments, monolingual learner's dictionaries for nonnative speakers have also started to address the blurred dividing line between general and specialised language, for example the Macmillan English Dictionary (MED):

people who use English in the workplace, or when studying subjects like medicine, business, or information technology expect their dictionary to explain the specialist terms they encounter on a regular basis [...] People studying to be doctors or nurses, for example, can now look up terms like ventricle, lymphocyte, carcinoma, and synovial fluid (Rundell, 2007).

Our experience shows that students are largely unfamiliar with dictionaries compiled specifically with English language learners in mind, so our special attention is given to this type of dictionary. This lack of familiarity is hardly surprising if we consider recent literature on dictionary use. Students do not use dictionaries effectively, do not seem to care much about the choice of resources they use and are tempted into using search engines and online resources of questionable reliability. At the same time, dictionary skills are taken for granted or not considered important enough to be taught as even many of the teachers remain unaware of the advancements and potential of digital dictionaries (Lew, 2013; Miller, 2017). The open, fast and free access to lexicographic information requires a new set of skills that will combine traditional dictionary skills with digital skills (Lew \& de Schryver, 2014). One of our aims is to promote the effective use of web-based lexicographic resources to help students distinguish between quality products which can satisfy their language and cognitive needs to help them complete their academic and professional tasks quickly and efficiently (see Tarp 2008). Drawing their 
attention to the relevance of all the aspects of the word beyond its meaning or equivalents (pronunciation, grammar information, usage labels, collocations, example sentences, regional variations, etc.), we aim to help them master their language skills autonomously through assisting in searching strategies and dictionary look-up results, helping to gain quick access to the right, contextually appropriate meaning of polysemous words and note semantic asymmetries and translation problems in the English-Spanish language pair (for example, illness versus disease, drug versus fármaco, medicamento). Concentrated on meaning and equivalents, students often ignore stylistic and discursive labels indicating register differences and restrictions of use. Exercises incorporated in the subject entail searching and analysing different types of information in dictionaries. Figure 1 shows an exercise aimed at strengthening students' understanding of connotation and pragmatic information offered in monolingual learner's dictionaries through examining the way it is presented by means of labels or incorporated in definitions.

Learner's dictionaries give us a lot of information about when and where a word or phrase is used. Find the underlined words in a dictionary and find out what special information they offer.

\begin{tabular}{|l|l|}
\hline Word & Label or information \\
\hline $\begin{array}{l}\text { During your pharmacy studies, you will spend a lot of time } \\
\text { in }\end{array}$ & \\
\hline $\begin{array}{l}\text { Some druggists went to work for pharmaceutical } \\
\text { companies. }\end{array}$ & \\
\hline He was such a skinny kid. & \\
\hline This treatment is unsuitable for elderly patients. & \\
\hline This website shows new jobs in pharma. & \\
\hline
\end{tabular}

Fig. 1 Exercise for pragmatic information in learner's dictionaries

Some of our vocabulary exercises are designed on the basis of authentic patient information leaflets. Figure 2 shows an excerpt from an exercise in which students are asked to identify the dosage form from the instructions for patients with the name of the form hidden. Next, from the completed texts they should extract the vocabulary needed to explain the use of the dosage form in question (Fig. 2).

Special attention is also given to word formation and how students can build on their previous knowledge to expand their vocabulary and, by extension, their pharmacy-related knowledge. Figure 3 shows an extract from an exercise in which students find the meaning of 18 prefixes commonly used in medical vocabulary with the help of examples of words containing them. Next, they should give more examples with the same prefix. In order to elicit specific terms with each prefix, a definition of a given word is displayed on the screen and students guess the term. 
Read the following dosage instructions and match them to the picture of the dosage form. Then, complete the table.

\begin{tabular}{|c|c|c|c|c|c|}
\hline & & & & & \\
\hline
\end{tabular}

\section{How to use AZOPT}

Only use AZOPT for your eyes. Do

not swallow or inject.

The recommended dose is 1 in the affected eye or eyes twice a day -morning and night.

If a goomisses your eye, try again.

If you get too much in your eyes, rinse it all out with warm water. Do not put in any more

How much to use

.The usual starting dose for adults and children over 6 years is 2 puffs four times a day

.Taking puffs at meal times and at bed time may help you to remember to take it

.Your doctor may tell you to take more or less puffs depending on how bad your asthma is. As your asthma gets better, your doctor may suggest that you reduce your daily dose to 2 puffs twice a day.

Remove the cap. Check the seal is not broken before you first use the

Then push the spike in the cap through the seal in the tube. Rub the skin.

Fig. 2 Dosage forms and related vocabulary

\section{PREFIXES}

Here there is a list of prefixes which are useful in helping you to understand unfamiliar words. Some of these words are used with a hyphen. Check in a dictionary if you're not sure. Read the examples, write the correct meaning next to each prefix and add one more example.

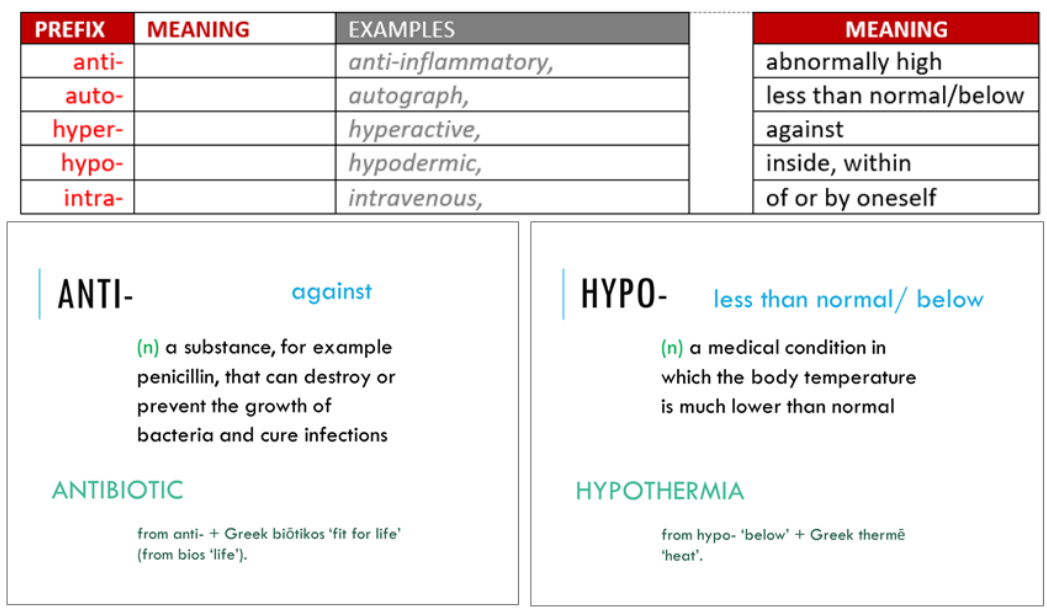

Fig.3 Prefixes used in medical vocabulary 


\subsection{English for Chemistry}

The first part of the course is dedicated mainly to communicative needs related to chemistry and chemical experiments and students are expected to complete two individual and one group tasks. In the first individual task, students record a podcast called 'What's the difference between ...?' about laboratory equipment. Each student prepares an educational radio programme for secondary school students about three laboratory items of their choice. The podcast should include clear definitions of each of the selected items explaining their appearance, functions and use. Next, students have to compare and contrast the items using a series of expressions practiced in class, e.g.: in contrast, whereas, both, differ in, are similar in, etc. The odd number of the items to be explained prompts the use of comparative and superlative forms of adjectives. As students can only use their voice and cannot support their explanations with images, they need to be as precise as possible so that their listeners would be able to identify the equipment if they entered a laboratory for the first time. Students submit their audio recording and the written text, and they are encouraged to practice and repeat the recording as many times as they wish and submit the best version. This task is directly linked and extends the activity developed in the first semester in the subject called Introduction to Laboratory Work. Most of the vocabulary related to laboratory equipment is first introduced in a CLIL activity called Hot-seat in which students prepare definitions in English for a list of selected laboratory items and participate in vocabulary games in class (García et al., 2018). This way, the first individual task is an opportunity to link content and language related to laboratory work.

For the second individual assignment, this time done in class time, students are asked to write two texts about a video showing an experiment of $\mathrm{pH}$ determination. The experiment was suggested by chemistry lecturers and the video was recorded with the help of one of them in the university laboratory, so in the setting and with supplies students are familiar with. With the sound off, the video is repeatedly played during the whole duration of the task, so students can check the details to be included at any time. Students are asked to mention all the materials given on the answer sheet (Fig. 4) and include all steps from the video, so that the experiment could be easily replicated. First, they should write direct instructions using imperative sentences which next are converted into a report using the passive voice. The idea for this task is based on the exercises in the classic book Basic English for Science (Donovan, 1978: 77-78). This task is a first step towards writing more advanced reports of students' experiments in the laboratory.

As far as group work about chemistry is concerned, students in groups of 3 or 4 give a presentation in which they explain an experiment previously carried out in the laboratory. The experiments (distillation, acid-base titration, melting point determination, liquidliquid extraction, vacuum filtration, and thin layer chromatography) were also suggested by chemistry lecturers and are purposefully simple to concentrate on communication and presentation skills along with the ability to adapt the presentation to teenagers as imaginary target audience. Students can support their presentation with images but cannot display slides containing written text. Although the task concentrates on the linguistic aspect of the project, which we, as language teachers, can evaluate and give feedback for, the subject matter knowledge is still important even for such an easy task. The content part is evaluated by an invited content teacher playing the role of an expert. The expert evaluates the content of the presentation (theoretical background, materials needed, safety precautions, and procedure) and at the end asks a few questions related to the experiment. For this reason, the category of 'expert questions' is also included in the evaluation rubric 
to see how the students can defend their ideas and arguments and react to the unexpected as a group.

\section{$\mathrm{pH}$ determination experiment}

Required equipment and supplies:
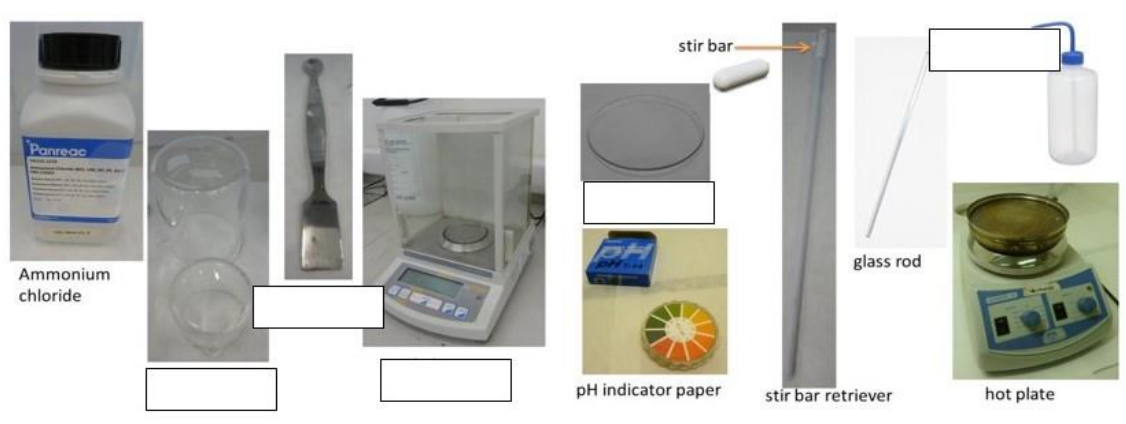

Fig. 4 Key vocabulary for Evaluated task 2

\subsection{English for Pharmaceutical Care}

Our students start to study Introduction to Pharmaceutical Care in the first year, but it is not until the third year that they study the main content matter of this area. This poses certain limitations on the tasks we can assign and the extent to which content knowledge can be involved. In the individual task, students are asked to produce an audio recording for a patient suffering from temporary vision loss, who is thus not able to read the patient information leaflet. The patient is a 50-year old man with constipation who is allergic to gelatine. First, students read two authentic patient information leaflets (Dulcobalance and Glycerol) to identify the suitable medicine for this patient. In their audio recording, they should justify their choice and explain usage and safety information covering all the points in the checklist provided in the rubric (for example, how often to take it, possible side effects, how to store it, etc.) adapting the written information from the leaflet to the audio format and avoiding verbatim repetitions from the leaflet or any technical language that could be incomprehensible to the patient. Specifically, they should ensure that the patient understands the meaning of laxative, dehydration and expiry date, so their definitions should be incorporated in their explanations. Conditionals are the main grammar focus of this task and at least one sentence with unless is requested. The pronunciation, intonation and pace are particularly important for this task as this time the students are not asked to submit the script and all the evaluation is based on their recording.

As for the second non-individual assignment, students are asked to record an 'In the Pharmacy' video that could be used by learners of English. The target of the video can be both pharmacists who attend patients in English and patients who need to go to a pharmacy abroad. In pairs, students are asked to record a dialogue concerning the purchase of medications for a typical holiday problem: mosquito bite, sunburn, or travel sickness. Again, the problems were selected with the help of the lecturer of Pharmaceutical Care. Since students have not studied 
prescription drugs yet, the dialogue can only refer to over-the-counter medicines for which a prescription is not required. Students are provided with links to webpages with reliable yet not too demanding information about these three common problems and their treatment to be used for the dialogue. Only the video is submitted to focus on oral skills (asking questions, giving advice, interaction) and students are provided with a checklist of the most important parts of the dialogue along with useful tips for the process of recording itself.

\section{CONCLUSION}

In this article, we set out to show that a language-focused ESP course is still needed in a CLIL setting, mainly to raise students' awareness of language and its role in disciplinary communication and to equip students with the necessary vocabulary, structures as well as learning strategies to complete their disciplinary tasks in English. The result of our course design is an eclectic, based on exercises and focused tasks that by some might be viewed as too traditional, conservative and too form-focused, but it embodies a balance between disciplinary language and content. Our materials and activities are linked to other activities carried out in English in the other Pharmacy subjects, so ESP and CLIL aim to complement each other to reinforce meaningful learning. However, as every content carries language and vice versa, the support from subject experts is crucial to effectively link language study to relevant academic content. The critical self-assessment of our materials and activities as well as feedback from content teachers and students have led to numerous changes and adaptations of our course and it will inevitably continue to change to adapt to the ever-evolving situation and new needs generated by the position of English in the degree programme. The main challenge lies in finding the right balance between students' language needs, pharmacyspecific language skills, and the language-related demands of pharmacy content subjects which integrate English. To this end, the ESP course is an ongoing process for which coordination and cooperation of all lecturers involved are of primary importance.

\section{REFERENCES}

Airey, J. (2016). EAP, EMI or CLIL? In K. Hyland \& P. Shaw (Eds.). The Routledge Handbook of English for Academic Purposes (pp. 71-83). Abingdon: Routledge.

Arnó-Macià, E., \& Mancho-Barés, G. (2015). The role of content and language in content and language integrated learning (CLIL) at university: Challenges and implications for ESP. English for Specific Purposes, 37, 63-73.

Coxhead, A. (2013). Vocabulary and ESP. In B. Paltridge \& S. Starfield (Eds.). The Handbook of English for Specific Purposes (pp. 115-32). Blackwell Handbooks in Linguistics. London: Wiley-Blackwell.

Coyle, D., Hood, P., \& Marsh, D. (2010). CLIL: Content and Language Integrated Learning. Cambridge University Press.

Donovan, P. (1978). Basic English for Science. Oxford: Oxford University Press.

Ellis, R. (2009). Task-based language teaching: Sorting out the misunderstandings. International Journal of Applied Linguistics, 19(3), 221-246. 
García, C., Crean, F., \& Woźniak, M. (2018). Hot-seat en el laboratorio: glosario de términos científicos en inglés. In D. Jiménez Sánchez (Ed.). VI Buenas Prácticas de Innovación Docente en el Espacio Europeo en Educación Superior (pp. 133-147). Villanueva de Gállego: Ediciones Universidad San Jorge.

González Ardeo, J. M. (2013). (In)compatibility of CLIL and ESP courses at university. Language Value, 5(1), 24-47.

Hutchinson, T., \& Waters, A. (1987). English for Specific Purposes: A Learning-Centred Approach. Cambridge: Cambridge University Press.

Leonardi, V. (2015). Bridging the gap between ESP and CLIL in the university context. Iperstoria - Testi Letterature Linguaggi, 5 (Spring), 18-26.

Lew, R. (2013). Online Dictionary Skills. In Electronic Lexicography in the 21st Century: Thinking Outside the Paper. Proceedings of the eLex Conference 17- 19 October 2013. http:// eki.ee/ elex2013/ proceedings/.

Lew, R., \& de Schryver, G.-M. (2014). Dictionary users in the digital revolution. International Journal of Lexicography, 27, (4), 341-359.

Miller, J. (2017). Learners' dictionaries of English. In P. Fuertes-Olivera (Ed.). The Routledge Handbook of Lexicography (pp. 353-366). London and New York: Taylor and Francis.

Rundell, M. (2007). Macmillan English Dictionary - How It Was Created. www.macmillandictionaries.com/ features/ how-dictionaries-are-written/ med/.

Tarnopolsky, O. (2013). Content-based instruction, CLIL, and immersion in teaching ESP at tertiary schools in non-English-speaking countries. Journal of ELT and Applied Linguistics (JELTAL), 1(1), 1-11.

Tarp, S. (2008). Lexicography in the Borderland Between Knowledge and NonKnowledge. Tübingen: Max Niemeyer Verlag.

Warburton, K. (2015). Managing Terminology in Commercial Environments. In H. J. Kockaert \& F. Steurs (Eds.). Handbook of Terminology, Vol. 1 (pp. 361- 392). Amsterdam/ Philadelphia: John Benjamins Publishing Company.

Webb, S. (2008). Receptive and Productive Vocabulary Sizes of L2 Learners. Studies in Second Language Acquisition, 30(1), 79-95.

Wolf, K. \& Stevens, E. (2007). The role of rubrics in advancing and assessing student learning. The Journal of Effective Teaching, 7(1), 3-14.

Woźniak, M. (2017). ESP in CLIL degree programmes. ESP Today - Journal of English for Specific Purposes at Tertiary Level, 5(2), 244-265.

Woźniak, M., Acebes de la Arada, D., Bergues Cabrales, J. M., García García, C. B., Giner Parache, B., Langa Morales, E., Lomba Eraso, L., \& Terrado Sieso, E. (2016). The perfect dose of Scientific English in Pharmacy: CLIL and ESP interconnections. In R. Breeze (Ed.). CLIL + Science: New Directions in Content and Language Integrated Learning for Science and Technology (unpaged). Navarra: Servicio de Publicaciones de la Universidad de Navarra.

Yang, W. (2016). ESP vs. CLIL: A coin of two sides or a continuum of two extremes? ESP Today - Journal of English for Specific Purposes at Tertiary Level, 4(1), 43-68. 